Sharif University of Technology
Scientia Iranica
Transactions E: Industrial Engineering
wCIENTIA

\title{
A fuzzy dynamic multi-objective multi-item model by considering customer satisfaction in a supply chain
}

\author{
S. Fazli Besheli ${ }^{a, *}$, R. Nemati Keshteli ${ }^{\mathrm{b}}$, S. Emami ${ }^{\mathrm{c}}$ and S.M. Rasouli ${ }^{\mathrm{a}}$ \\ a. Department of Industrial Engineering, Mazandaran Institute of Technology, Babol, Mazandaran, P.O. Box 744, Iran. \\ b. Faculty of Engineering, University of Guilan, East Guilan, Rasht, P.O. Box 1841, Iran. \\ c. Department of Industrial Engineering, Babol Noshirvani University of Technology, Babol, Mazandaran, P.O. Box 484, Iran.
}

Received 2 February 2016; received in revised form 20 July 2016; accepted 1 October 2016

\author{
KEYWORDS \\ Supply chain \\ optimization; \\ Transportation risk; \\ Customer satisfaction; \\ Quality.
}

\begin{abstract}
Customer satisfaction is an important issue in competitive strategic management of companies. Logistical and cross-functional drivers of supply chain have an important role in managing customer satisfaction. Customer satisfaction depends on quality, cost, and delivery. In this paper, a fuzzy mixed integer nonlinear programming model is proposed for a multi-item multi-period problem in a multi-level supply chain. Minimization of costs, manufacturing and transportation time, transportation risks, maximization of quality by minimizing the number of defective products, and maximization of customers' service levels are considered to be objective functions of the model. Furthermore, it is assumed that the demand rates are fuzzy values. An exact $\varepsilon$-constraint approach is used to solve the problem. The problem is computationally intractable. Therefore, the Non-dominant Sorting Genetic Algorithm (NSGA-II) is developed to solve it. The Taguchi method is utilized to tune the NSGA-II parameters. Finally, some numerical examples are generated and solved to evaluate the performance of the proposed model and solving methods.
\end{abstract}

(C) 2017 Sharif University of Technology. All rights reserved.

\section{Introduction}

Supply Chain Management (SCM) has important effects on the surviving of companies in competitive markets. The goal of classical Supply Chain (SC) problems is to send products between layers to supply the demands of customers while minimizing the inventory costs [1]. Many researchers have focused on the integration of suppliers, manufacturing plants, distribution centers, and customers. Increasing competitions are forcing some businesses which urge them to pay much more attention to customers satisfaction,

\footnotetext{
*. Corresponding author. Tel./Fax: +98 1132163215 E-mail addresses: Shabnam.Fazli@mit.ac.ir (S. Fazli Besheli); r.nemati@Guilan.ac.ir (R. Nemati Keshteli); s_emami@nit.ac.ir (S. Emami); Mansooreh.Rasouli@mit.ac.ir (S.M. Rasouli)
}

e.g. by providing strong customer services. Customer satisfaction is considered as a key factor in every SC. There is more to say about customer satisfaction than customer services. There are several factors that influence customer's decisions. Appropriate prices, highquality products, on-time and appropriate delivery of required amount of products influence customers positively [2].

In this paper, a multi-period multi-product fourlayer SC consists of suppliers, manufacturing plants, distribution centers, and customers (considering retailers or end customers). Customers' demands are assumed to be fuzzy values. There are five goals in the proposed model as follows: minimizing the inventory costs, minimizing the number of defective products, minimizing the manufacturing and transportation times, maximizing the quantity of perfect products, and minimizing the transportation risks between manufacturing plants and distribution centers. 
The problem is solved by using Non-dominated Sorting Genetic Algorithm (NSGA-II) [3] and $\varepsilon$-constraint [4] methods.

\section{Literature review}

One of the inevitable difficulties in the manufacturing industries, which leads to customers' dissatisfaction, is the failure rate in production. Also, risks and uncertainty in the SC lead to reducing service level. Delaying in the delivery of finished products is another factor that creates customer dissatisfaction. In fact, customers will be satisfied if they receive enough products with good quality at the right time and place. SC optimization is a critical task for manufacturing companies. Inventory management plays an important role in reducing the total costs of SC. Harris [5] proposed that the most well-known model to control inventories is the classical Economic Order Quantity (EOQ). Miller [6] presented a multi-item single-period model whose objectives are to minimize backorders and consider budget constraints. Kirkpatrik et al. [7] developed one-product multi-period managing inventory model. Das et al. [8] presented a multi-item inventory model with constant demand and infinite replenishment. Clark [9] started the studies on a two-layer SC in 1960. Veinott and Bessler [10] developed this model in another study. Goyal [11] presented the joint optimization concept for both vendors and buyers. Hsiao et al. [12] developed a model of Economic Order Quantity (EOQ) in the SC. Abdul-Jabbar et al. [13] presented a two-layer SCM with a single vendor and multi buyers. Taleizadeh et al. [14] developed a multi-product model with a singlevendor, multi-buyer with variable lead time. Sadeghi et al. [15] developed a constrained MV-MR-SW, SC in which both the space and annual number of orders of the central warehouse are limited. The goal is to find the order quantities along with the number of shipments received by retailers and vendors so that the total inventory cost of the chain can be minimized. Varyani et al. [16] considered a three-layer integrated production inventory model consisting of a central warehouse and a manufacturer including two independent departments as processing and assembly parts.

Pasandideh et al. [17] presented a bi-objective multi-product multi-period three-layer mathematical modeling under uncertain environments. In order to make the problem close to a real situation, the majority of the parameters in this network, including fixed and variable costs, customer demands, available production time, set-up and production times, are all considered as stochastic. Pasandideh et al. [18] developed a bi-objective multi-item multi-period threelayer SC network with warehouse reliability in which the two objectives are minimizing the total costs while maximizing the average number of products dispatched to customers. Sadeghi et al. [19] developed a multiobjective evolutionary algorithm for a bi-objective vendor managed inventory model in which demands are considered as trapezoidal fuzzy numbers. The two objectives of this model are minimizing warehouse space and costs. Sarrafha et al. [20] proposed a bi-objective mixed-integer nonlinear programming for integrated production, procurement and distribution problem which minimizes costs and the average tardiness of products to distribution centers.

Many researchers have focused on the factors influencing the customer satisfaction. It is assumed that customer satisfaction caused by product quality affects corporation performance since it is surmised that customers will buy a product from companies they will be satisfied with, i.e., such products that will meet their expectations [21]. Kamali et al. [22] developed a multi-objective quantity discount and joint optimization model for coordination of a single-buyer multi-vendor SC in which product quality is considered as an objective function. Mortezaei et al. [23] proposed a bi-objective linear model which tries to minimize the total costs and maximize customer service levels simultaneously. Uncertainty and risk in the SC lead to reducing the service levels to customers. Risks are typically classified as systematic and unsystematic risks. Arabzad et al. [24] presented a new multiobjective location-inventory model in a distribution network with transportation modes. This paper considers the optimization of multiple objectives such as minimizing costs, total earliness and tardiness, and total deteriorated items during transportation in distribution centers. Sadeghi et al. [25] developed a VMI model in a multi-retailor single-vendor SCM which aims to find the optimal retailers' order quantities so that the total inventory and transportation costs can be minimized while several constraints are satisfied.

In order to solve multi-objective problems, many authors have proposed meta-heuristic algorithms. The Non-dominated Sorting Genetic Algorithm (NSGA-II) is a Multi-Objective Evolutionary Algorithm (MOEA) that has been applied to find Pareto front solutions in different fields of studies. Sadeghi and Niaki [26] applied NSGA-II to solve a multi-objective vendormanaged inventory problem with trapezoidal fuzzy demands. Mousavi et al. [27] presented a seasonal multi-product multi-period inventory control model with inventory costs obtained under inflation and allunit discount policies in which a multi-objective optimization algorithm of Non-dominated Sorting Genetic Algorithm (NSGA-II) is used to solve the problem. Pasandideh et al. [17] used a Non-dominated Sorting Genetic Algorithm (NSGA-II) to solve the proposed complicated bi-objective multi-product multi-period three-layer SC network problem. Some authors have employed the $\varepsilon$-constraint method to find Pareto so- 
Table 1. Some articles related to customer satisfaction in SCM.

\begin{tabular}{|c|c|c|c|c|c|c|c|}
\hline \multirow[b]{2}{*}{ Rows } & \multirow[b]{2}{*}{ Year } & \multirow[b]{2}{*}{ Authors } & \multicolumn{4}{|c|}{ Objective functions } & \multirow[b]{2}{*}{$\begin{array}{c}\text { Max.b }^{b} \\
\text { service } \\
\text { level }\end{array}$} \\
\hline & & & $\begin{array}{l}\text { Min. }^{\mathrm{a}} \\
\text { inventory } \\
\text { costs }\end{array}$ & $\begin{array}{c}\text { Min. }^{\text {a }} \text { delivery \& } \\
\text { manufact uring } \\
\text { times }\end{array}$ & $\begin{array}{l}\text { Max. }^{b} \\
\text { quality }^{2}\end{array}$ & $\begin{array}{c}\text { Min. }^{\mathrm{a}} \\
\text { transportation }^{\text {risk }}\end{array}$ & \\
\hline 1 & 2011 & Kamali et al. & $\checkmark$ & $\checkmark$ & $\checkmark$ & & \\
\hline 2 & 2014 & Yu et al. & $\checkmark$ & & & $\checkmark$ & \\
\hline 3 & 2014 & Arabzad et al & $\checkmark$ & $\checkmark$ & $\checkmark$ & & \\
\hline 4 & 2015 & Sarrafha et al. & $\checkmark$ & $\checkmark$ & & & \\
\hline 5 & 2015 & Mortezaei et al. & $\checkmark$ & & & & $\checkmark$ \\
\hline
\end{tabular}

${ }^{\mathrm{a}}$ Minimizing; ${ }^{\mathrm{b}}$ Maximizing.

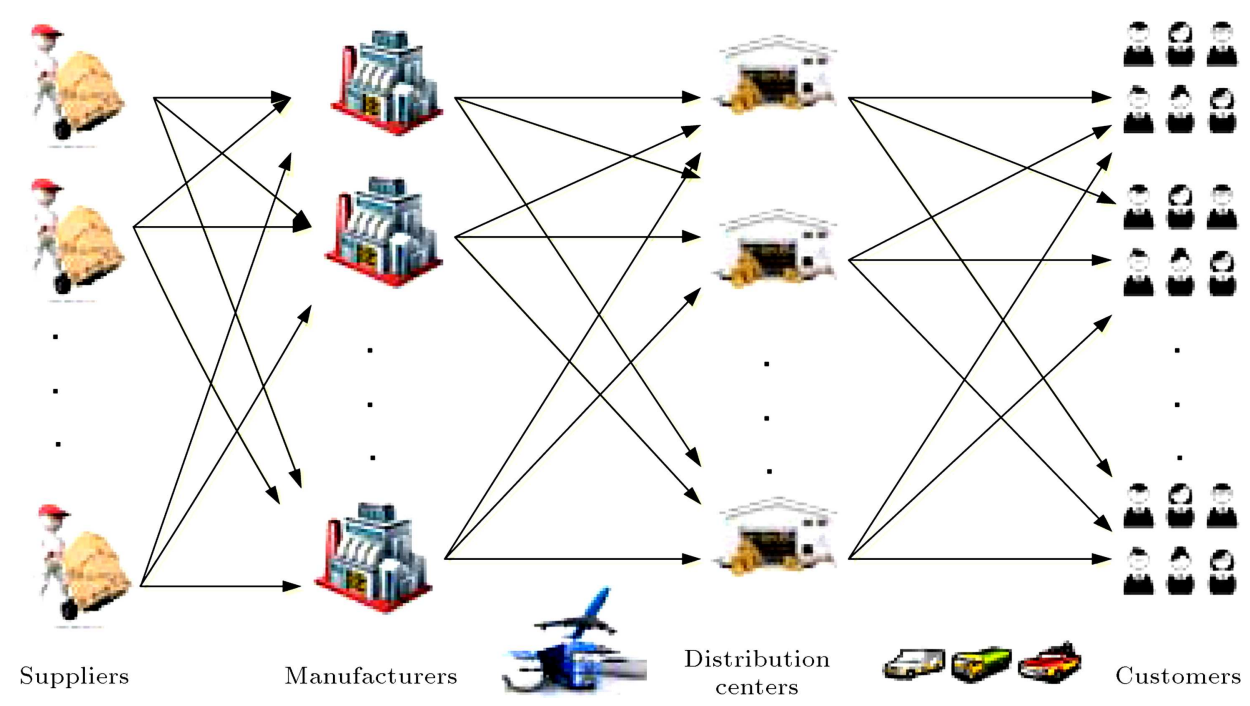

Figure 1. Four-layer SC of the proposed model.

lutions to the multi-objective problems [28,29]. Yu et al. [30] presented a bi-objective model under uncertainty in which minimizing costs and risks are considered as the two objectives.

Literature review shows that all important factors affecting customer satisfaction, such as quality, cost, delivery, etc., are not considered together in one model (Table 1).

A new multi-product multi-period multi-objective $\mathrm{SC}$ model is proposed in this paper to minimize the total inventory costs while maximizing customers' satisfaction. The rest of this paper is organized as follows. Problem definition and mathematical formulations of the model are given in Section 3. Section 4 presents the solving procedure of the proposed model. Conclusions and further studies are presented in Section 5 .

\section{Problem definition}

The proposed model follows two main objectives as reducing inventory costs in four-layer SC and achieving maximum customer satisfaction. Similar to Kamali et al. [22], we suppose that customer satisfaction can be increased by minimizing failure quantity. We consider lower prices for imperfect items. Inspection and rework costs are added to the model. In addition, it is supposed that the higher level of quality can lead to an increase in time that is not pleasant for customers. This model uses the model presented by Arabzad et al. [24] considering the risk of vehicles to select the best vehicles between manufacturers and distribution centers. Also, due to the defective products, increasing customer service levels is very important. Mortezaie et al. [23] maximized service levels by minimizing the ratio of delivered items and demands. Figure 1 represents the network of four-layer SC of the model.

\subsection{Notations and assumptions}

To extend the mathematical model, the indices, parameters, and decision variables adopted in this paper are as follows:

\section{Indices}

$i \quad$ An index for manufactured items,

$$
i=1,2, \cdots, I
$$


$m \quad$ An index for manufacturers, $m=1,2, \cdots, M$

$d \quad$ An index for distribution center, $d=1,2, \cdots, D$

$s \quad$ An index for supplier, $s=1,2, \cdots, S$

$t \quad$ An index for periods, $t=1,2, \cdots, T$

$i^{\prime} \quad$ An index for raw materials, $i^{\prime}=$ $1,2, \cdots, I^{\prime}$

c An index for customers, $c=1,2, \cdots, C$

$f \quad$ An index for vehicles between manufacturers and distribution centers, $d, f=1,2, \cdots, F$

$v \quad$ An index for vehicles between distribution centers and customers, $v=1,2, \cdots, V$

\section{Parameters}

$O_{m d t}^{i}$

Ordering cost of item $i$ ordered from distribution center $c$ to manufacturer $m$ per unit time $t$

$R M P^{i^{\prime} i} \quad$ Usage percent of raw material $i$ for manufacturing each unit of item $i$

$D_{m d t}^{i} \quad$ Demand rate of distribution center $d$ of item $i$ manufactured at manufacturer $m$ at period $t$

$\tilde{D}_{c t}^{i} \quad$ Demand rate of customer $c$ for item $i$ at period $t$

$D_{s m t}^{i^{\prime}} \quad$ Demand rate of manufacturer $m$ of item $i^{\prime}$ which is supplied from supplier $m$ at period $t$

$T(P)_{m t}^{i} \quad$ Required time for manufacturing item $i$ at manufacturer $m$ at period $t$

$T(S)_{m d t}^{f i} \quad$ Required time for transporting item $i$ from manufacturer $m$ to distribution center $d$ by vehicle $f$ at period $t$

$T(S)_{d c t}^{v i} \quad$ Required time for transporting item $i$ from distribution center $d$ to customer $c$ by vehicle $v$ at period $t$

$C(T)_{m d t}^{f i} \quad$ Shipment cost for vehicle $f$ per item $i$ from manufacturer $m$ to distribution center $d$ at period $t$

$C(T)_{d c t}^{v i} \quad$ Shipment cost for vehicle $v$ per item $i$ from distribution center $d$ to customer $c$ at period $t$

$C(Q)_{m t}^{i} \quad$ Quality cost per item $i$ manufactured at manufacturer $m$ at period $t$

$C(P 1)_{m d t}^{f i} \quad$ Purchasing cost of perfect item $i$ which is shipped by vehicle $f$ from manufacturer $m$ to distribution center $d$ at period $t$
$C(P 2)_{m d t}^{f i} \quad$ Purchasing cost of imperfect item $i$ which is shipped by vehicle $f$ from manufacturer $m$ to distribution center $d$ at period $t$

$C(P)_{\text {smt }}^{i^{\prime}} \quad$ Purchasing cost of raw material $i^{\prime}$ which is purchased from supplier $s$ to manufacturer $m$ at period $t$

$\pi_{m d t}^{f i}$

$C(M)_{m t}^{i}$

Lost sale cost per item $i$ that is not delivered to distribution center $d$ at period $t$

$C(H)_{m t}^{i} \quad$ Inventory holding cost per unit of item $i$ for manufacturer $m$ at period $t$

$C(H)_{m t}^{i^{\prime}} \quad$ Inventory holding cost per unit of raw material $i^{\prime}$ for manufacturer $m$ at period $t$

$C(H)_{d t}^{i} \quad$ Inventory holding cost per unit of item $i$ for distribution center $d$ at period $t$

$I R_{m d t}^{f i} \quad$ Financial loss of vehicle $f$ risk for shipping item $i$ from manufacturer $m$ to distribution center $d$ at period $t$

$R(U)_{m d t}^{f i} \quad$ Maximum allowable risk for shipping item $i$ with vehicle $f$ from manufacturer $m$ to distribution center $d$ at period $t$

$P(S)_{m d t}^{f i} \quad$ Probability of risk for shipping item $i$ with vehicle $f$ from manufacturer $m$ to distribution center $d$ at period $t$

$E \quad$ Nonproductive time, a constant value

$\varepsilon \quad$ A very small number

$X 1 \quad$ Minimum defective and imperfect rate

$X 2 \quad$ Maximum defective rate

$R_{m d t}^{f i} \quad$ Risk of vehicle $f$ for shipping item $i$ from manufacturer $m$ to distribution center $d$ at period $t$

$C_{d t}^{i} \quad$ Capacity of distribution center $d$ for item $i$ at period $t$

$C_{m t}^{i} \quad$ Capacity of manufacturer $m$ for item $i$ at period $t$

$C_{t}^{f} \quad$ Capacity of vehicle $f$ at period $t$

$C_{t}^{v} \quad$ Capacity of vehicle $v$ at period $t$

Decision variables

$\alpha_{m d t}^{f i} \quad$ Perfect quantity of item $i$ shipped from manufacturer $m$ to distribution center $d$ by vehicle $f$ at period $t$

$\beta_{m d t}^{f i} \quad$ Defective and imperfect quantity of item $i$ shipped from manufacturer $m$ to distribution center $d$ by vehicle $f$ at period $t$ 
$\gamma_{m d t}^{f i} \quad$ Defective quantity of item $i$ shipped from manufacturer $m$ to distribution center $d$ by vehicle $f$ at period $t$

$\eta_{m d t}^{f i} \quad$ Imperfect quantity of item $i$ shipped from manufacturer $m$ to distribution center $d$ by vehicle $f$ at period $t$ which is lost sale

$q_{m d t}^{f i} \quad$ Delivery quantity of item $i$ shipped from manufacturer $m$ to distribution center $d$ by vehicle $f$ at period $t$

$q_{d c t}^{v i} \quad$ Delivery quantity of item $i$ shipped from distribution center $d$ to manufacturer $m$ by vehicle $v$ at period $t$

$q_{s m t}^{i^{\prime}} \quad$ Delivery quantity of raw material $i^{\prime}$ shipped from supplier $s$ to manufacturer $m$ at period $t$

$q_{d c t}^{i} \quad$ Delivery quantity of item $i$ shipped from distribution center $d$ to customer $c$ at period $t$

$P_{m t}^{i} \quad$ Production quantity of item $i$ for manufacturer $m$ at period $t$

$I_{m t}^{i} \quad$ Inventory level of item $i$ for manufacturer $m$ at period $t$

$I_{d t}^{i} \quad$ Inventory level of item $i$ for distribution center $d$ at period $t$

$z_{m d t}^{f i} \quad$ A binary decision variable; set equal to one if vehicle $f$ delivers item $i$ from manufacturer $m$ to distribution center $d$ at period $t$, and zero otherwise

$z_{d c t}^{v i} \quad$ A binary decision variable; set equal to one if vehicle $v$ delivers item $i$ from distribution center $d$ to customer $c$ at period $t$, and zero otherwise

Moreover, the assumptions involved in the problem are:

I. Selecting suppliers and distributors is considered for strategic levels;

II. Assigning products to the distribution channels and selecting the shortest routes from manufacturing plants to distribution centers are considered as tactical decisions;

III. Determining quantity of manufactured items per plant per period, inventory levels in distribution centers and factories, the lost sale quantity per period, the amount of raw material shipped from suppliers to manufacturers are all SC planning decisions;

IV. Manufactured items include three parts: perfect, imperfect, and defective items;

$\mathrm{V}$. Manufacturers suggest lower prices for imperfect items;
VI. Lost sales are defective items;

VII. The model considers creating costs for appropriate levels of quality;

VIII. High number of perfect items is considered as high quality which makes customer satisfied;

IX. Different vehicles can be selected for different periods;

X. Purchasing costs are different for periods;

XI. To make the model more realistic, customers' demands are considered as fuzzy numbers.

\subsection{Mathematical formulations of model}

Mathematical mixed-integer non-linear programming of the proposed model is as follows:

$$
\begin{aligned}
& T O C=\sum_{i=1}^{I} \sum_{m=1}^{M} \sum_{d=1}^{D} \sum_{t=1}^{T}\left(O_{m d t}^{i} \times \frac{q_{m d t}^{f i}}{q_{m d t}^{f i}+\varepsilon}\right) \\
& T S C_{m d}=\sum_{i=1}^{I} \sum_{m=1}^{M} \sum_{d=1}^{D} \sum_{f=1}^{F} \sum_{t=1}^{T}\left[C(T)_{m d t}^{f i} \times q_{m d t}^{f i} \times z_{m d t}^{f i}\right] \\
& T S C_{d c}=\sum_{i=1}^{I} \sum_{d=1}^{D} \sum_{c=1}^{C} \sum_{v=1}^{V} \sum_{t=1}^{T}\left[C(T)_{d c t}^{v i} \times q_{d c t}^{v i} \times z_{d c t}^{v i}\right] \\
& T B C=\sum_{i=1}^{I} \sum_{m=1}^{M} \sum_{d=1}^{D} \sum_{f=1}^{F} \sum_{t=1}^{T}\left(\pi_{m d t}^{f i} \times \eta_{m d t}^{f i}\right), \\
& T M C=\sum_{i=1}^{I} \sum_{m=1}^{M} \sum_{t=1}^{T}\left[C(M)_{m t}^{i} \times\left(P_{m t}^{i}\right)\right] \\
& T H C=\sum_{i=1}^{I} \sum_{m=1}^{M} \sum_{t=1}^{T}\left(C(H)_{m t}^{i} \times I_{m t}^{i}\right) \\
& +\sum_{i=1}^{I} \sum_{d=1}^{D} \sum_{t=1}^{T}\left(C(H)_{d t}^{i} \times I_{d t}^{i}\right) \\
& T R C=\sum_{i=1}^{I} \sum_{m=1}^{M} \sum_{d=1}^{D} \sum_{t=1}^{T} \sum_{f=1}^{F}\left(I R_{m d t}^{f i} \times z_{m d t}^{f i}\right), \\
& T Q C=\sum_{i=1}^{I} \sum_{m=1}^{M} \sum_{d=1}^{D} \sum_{t=1}^{T}\left(C(Q)_{m t}^{i} \times P_{m t}^{i}\right), \\
& T P C=\sum_{i^{\prime}=1}^{I^{\prime}} \sum_{s=1}^{S} \sum_{m=1}^{M} \sum_{t=1}^{T}\left(C(P)_{s m t}^{i^{\prime}} \times q_{s m t}^{i^{\prime}}\right) \\
& +\sum_{i=1}^{I} \sum_{m=1}^{M} \sum_{d=1}^{D} \sum_{f=1}^{F} \sum_{t=1}^{T}\left[\left(C(P 2)_{m d t}^{f i} \times \gamma_{m d t}^{f i}\right)\right]
\end{aligned}
$$




$$
+\sum_{i=1}^{I} \sum_{m=1}^{M} \sum_{d=1}^{D} \sum_{f=1}^{F} \sum_{t=1}^{T}\left(C(P 1)_{m d t}^{f i} \times \alpha_{m d t}^{f i}\right)
$$

$$
\begin{aligned}
& \min Z_{1}= T O C+T S C+T B C+T M C+T H C \\
&+T R C+T P C+T Q C \\
& \min Z_{2}= \sum_{i=1}^{I} \sum_{m=1}^{M} \sum_{d=1}^{D} \sum_{f=1}^{F} \sum_{t=1}^{T}\left(\beta_{m d t}^{f i}\right) \\
& \min Z_{3}= \sum_{i=1}^{I} \sum_{m=1}^{M} \sum_{t=1}^{T}\left(T(P)_{m t}^{i} \times P_{m t}^{i}\right) \\
&+\sum_{i=1}^{I} \sum_{m=1}^{M} \sum_{d=1}^{D} \sum_{t=1}^{T} \sum_{f=1}^{F}\left(T(S)_{m d t}^{f i} \times z_{m d t}^{f i}\right) \\
&+\sum_{i=1}^{I} \sum_{d=1}^{D} \sum_{c=1}^{C} \sum_{v=1}^{V} \sum_{t=1}^{T}\left(T(S)_{c d t}^{v i} \times z_{c d t}^{v i}\right)+E \\
& \sum_{i=1}^{I} \sum_{m=1}^{M} \sum_{d=1}^{D} \sum_{f=1}^{F} \sum_{t=1}^{T}\left(\alpha_{m d t}^{f i}\right) \\
& \sum_{i=1}^{I} \sum_{m=1}^{M} \sum_{d=1}^{D} \sum_{t=1}^{T}\left(D_{m d t}^{i}\right)(13) \\
&\left.\max Z_{4}\right) \\
& \min Z_{5}= \sum_{i=1}^{I} \sum_{m=1}^{M} \sum_{d=1}^{D} \sum_{f=1}^{F} \sum_{t=1}^{T}\left(R_{m d t}^{f i} \times Z_{m d t}^{f i}\right), \quad(14)
\end{aligned}
$$

S.t.:

$$
\begin{array}{ll}
\left(I_{m, t-1}^{i}+P_{m t}^{i}\right) \leq C_{m t}^{i}, & \forall i, m, t, \\
I_{d t}^{i}+\sum_{m=1}^{M} q_{m d t}^{f i}=C_{d t}^{i}, & \forall f, i, d, t, \\
\left(q_{m d t}^{f i} \times z_{m d t}^{f i}\right) \leq C_{t}^{f}, & \forall i, m, d, t, f, \\
\left(q_{d c t}^{v i} \times z_{d c t}^{v i}\right) \leq C_{t}^{v}, & \forall i, c, d, t, v, \\
\sum_{d=1}^{D} \sum_{v=1}^{V} q_{d c t}^{v i} \leq \tilde{D}_{c t}^{i}, & \forall i, c, t, \\
\sum_{d=1}^{D} \sum_{v=1}^{V} q_{d c t}^{v i} \leq \sum_{m=1}^{M}\left(q_{m d t}^{f i}-\eta_{m d t}^{f i}\right), \quad \forall f, i, c, t \\
\sum_{f=1}^{F} z_{m d t}^{f i}=1, \\
\sum_{v=1}^{V} z_{d c t}^{v i}=1, \\
\forall i, m, d, t
\end{array}
$$

$$
\begin{aligned}
& \sum_{s=1}^{S} q_{s m t}^{i^{\prime}} \geq R M P^{i^{\prime} i} \times P_{m t}^{i}, \quad \forall i^{\prime}, i, m, t \\
& P_{m t}^{i}=I_{m t}^{i}+\sum_{d=1}^{D} q_{m d t}^{f i}, \quad \forall f, i, m, t, \\
& R_{m d t}^{f i}=P(S)_{m d t}^{f i} \times I R_{m d t}^{f i}, \quad \forall f, i, m, d, t, \\
& R_{m d t}^{f i} \times z_{m d t}^{f i} \leq R(U)_{m d t}^{f i}, \quad \forall f, i, m, d, t, \\
& \beta_{m d t}^{f i}=\eta_{m d t}^{f i}+\gamma_{m d t}^{f i}, \quad \forall f, i, m, d, t, \\
& \sum_{f=1}^{F} \alpha_{m d t}^{f i} \leq D_{m d t}^{i}, \quad \forall f, i, m, d, t, \\
& q_{m d t}^{f i}=\beta_{m d t}^{f i}+\alpha_{m d t}^{f i}, \quad \forall f, i, m, d, t, \\
& \beta_{m d t}^{f i} \geq X 1 \times q_{m d t}^{f i}, \quad \forall f, i, m, d, t, \\
& \alpha_{m d t}^{f i} \leq(1-X 1) \times q_{m d t}^{f i}, \quad \forall f, i, m, d, t, \\
& \gamma_{m d t}^{f i} \leq X 2 \times \beta_{m d t}^{f i}, \quad \forall f, i, m, d, t, \\
& \gamma_{m d t}^{f i} \geq(1-X 2) \times \beta_{m d t}^{f i}, \quad \forall f, i, m, d, t, \\
& \alpha_{m d t}^{f i}, \beta_{m d t}^{f i}, \gamma_{m d t}^{f i}, \eta_{m d t}^{f i}, q_{m d t}^{f i}, P_{m t}^{i}, q_{s m t}^{i^{\prime}}, q_{d c t}^{v i}, \\
& I_{m t}^{i}, I_{d t}^{i}, I_{m t}^{i^{\prime}} \geq 0, \\
& z_{m d t}^{f i}, z_{m d t}^{v i}, z_{m t}^{i} \in\{0,1\} .
\end{aligned}
$$

Eq. (1) calculates the total ordering costs of distribution center $d$. Eqs. (2) and (3) represent transportation costs of vehicles $f$ and $v$, respectively. Eq. (4) shows the lost sale costs of defective items. Eq. (5) calculates manufacturing costs. Total inventory costs of manufactured items and raw materials are obtained by Eq. (6). Financial losses resulting from transportation risk are obtained by Eq. (7). Eq. (8) represents the providing quality costs. Formula Eq. (9) calculates the total purchasing cost of SC. The total inventory costs of SC are obtained by Eq. (10). Quality function is represented in Eq. (11). The third objective aims to maximize customer satisfaction by minimizing manufacturing and shipping costs which are obtained by Eq. (12). Eq. (13) represents service levels. The fifth objective function minimizes transportation risks and is calculated by Eq. (14). Eqs. (15) to (34) are constraints of the proposed models. Constraints (15) and (16) show delivery quantity and inventory levels which should be equal to the capacity of manufacturers and distributors, so delivery quantities are less than or equal to capacities represented in Constraints (17) 
and (18). Constraint (19) shows that delivery quantity from distribution centers to customers is equal to or less than customers' demands. Constraint (20) represents the balancing equation for distribution centers. Constraints (21) and (22) show that only one type of vehicle can be selected for each item at every period in each channel. It is obvious that raw materials delivered to manufacturers should be equal to or more than their needs. This constraint is represented in Eq. (23). Quantity of manufactured items is equal to inventory levels and delivery quantity. This constraint is shown in Constraint (24). Constraint (25) calculates risk levels. The maximum allowable risk is obtained by Constraint (26). Quantity of perfect items should be less than demands. This limitation is represented by Constraint (28). Constraint (29) shows delivery quantity consisting of perfect, imperfect, and defective items. This model considers minimum rates for defective and imperfect items shown in Eqs. (30) to (33). The two remaining equations define the value ranges of variables.

\section{Solving procedure of the proposed model}

The NSGA_II algorithm [3] is developed to solve the proposed multi-objective model. Moreover, the $\varepsilon$ constraint method is employed to validate the obtained results. Finally, some numerical examples are generated to analyze and compare the solving methods.

\subsection{E-constraint method}

Abounacer [31] expressed that the $\varepsilon$-constraint method solves a set of constrained single-objective problems $P^{k}(\varepsilon), \varepsilon=\left(\varepsilon_{1}, \cdots, \varepsilon_{k-1}, \varepsilon_{k+1}, \cdots, \varepsilon_{m}\right)$ obtained by choosing one objective, $f_{k}$, as the only objective to optimize and incorporate inequality constraints for the remaining objectives of the form $f_{i} \leq \varepsilon, i=$ $1, \cdots, k-1, k=1, \cdots, m$. The set of problems, $P^{k}(\varepsilon)$, is obtained by assigning different values to the components of the $\varepsilon$-vector. In the proposed model, minimizing the total costs of SC is selected as the main objective function and other functions are considered as constraints. By assessing different combinations provided by values in $\varepsilon$-vectors, the best combination has been obtained. Table 2 represents $\varepsilon$-vectors of the four remaining objective functions.

Different combinations provided from $\varepsilon$-vectors and SC costs are examined for these combinations. Due to the large number of combinations, just a number

Table 2. $\varepsilon$-vectors for objective functions.

\begin{tabular}{ccccc}
\hline Functions & Quality & Service level & Time & Risk \\
\hline$\varepsilon_{1}$ & 0 & 0 & 227 & 2070.25 \\
$\varepsilon_{2}$ & 9450 & 0.4705 & 9684.5 & 1414.25 \\
$\varepsilon_{3}$ & 18900 & 0.941 & 19142 & 3484.5 \\
\hline
\end{tabular}

of solutions for cost function are shown in Table 3 for the cost function of SCM in one of the provided examples. As obvious, the best combination is the one that minimizes costs to the extent that the variables get reliable values in the problem, not zero values as highlighted in Table 3 .

\subsection{Non-dominant sorting genetic algorithm}

NSGA-II algorithm is one of the most applicable algorithms to solve multi-objective optimization problems [24]. NSGA-II generates a parent population of size $n$ Pop. Then, the objective values are evaluated by using an evaluation function during several generations. To create Pareto fronts, the population is ranked based on non-dominant sorting procedures. Each individual of the population obtains a rank based on its level (1 is the best level, 2 is the second best level, and so on). The crowding distance between members is obtained for each front. First, a binary tournament selection operator is used which helps to select two members among the population. Next, a new population of offspring with the size of $n$ is created by using simulated binary crossover (SBX) operator. It is used to create the population consisting of the current and the new population of size $(n P o p+n)$. Finally, a population of $n P o p$ size is obtained by sorting. The new population is used to generate the next new offspring by repeating these steps until the stopping condition is met.

\subsubsection{Encoding and decoding the algorithm}

A proper chromosome representation can lead to more efficient performance of NSGA-II. In many inventory controls and SC problems, to produce a proper chromosome in the initial population, the relationship between different levels of the SC is considered as different parts of chromosomes. Altiparmak et al. [32] proposed an illustration of chromosomes, considering a threelayer SC. They also proposed a repair algorithm, which is used when the total capacity of opened DCs or plants is not enough to meet customer demands. A representation of chromosome with different sections of $\mathrm{SC}$ in the proposed model along with a two-layer $\mathrm{SC}$ with two products, two raw materials, two suppliers, manufacturers, distributors and customers, which consists two strings, is shown in Figure 2.

Given that, a random method to produce the initial population of chromosomes without a proper repair algorithm may lead to an infeasible solution.

To be more specific, in this paper, a chromosome consists of one section. This section is organized according to the relationship between distributors and customers with the length of $I(D+C)$ represented by $T$ strings, where $T$ is a fixed number of periods. In this method, each gene on the proposed chromosome is not permuted randomly (according to distributors' capacities and customers' demands) from $\left[1, I^{*}(C+\right.$ 
Table 3. Cost function values for different combinations of other functions' $\varepsilon$-vectors.

\begin{tabular}{|c|c|c|c|c|c|c|c|c|c|}
\hline $\begin{array}{c}\varepsilon \\
\text { (quality) }\end{array}$ & $\begin{array}{c}\varepsilon \\
\text { (service } \\
\text { level) }\end{array}$ & $\begin{array}{c}\varepsilon \\
\text { (time) }\end{array}$ & $\begin{array}{c}\varepsilon \\
\text { (risk) }\end{array}$ & $\begin{array}{l}\text { Total cost } \\
\text { value }\end{array}$ & $\begin{array}{c}\varepsilon \\
\text { (quality) }\end{array}$ & $\begin{array}{c}\varepsilon \\
\text { (service } \\
\text { level) }\end{array}$ & $\begin{array}{c}\varepsilon \\
\text { (time) }\end{array}$ & $\begin{array}{c}\varepsilon \\
\text { (risk) }\end{array}$ & $\begin{array}{l}\text { Total cost } \\
\text { value }\end{array}$ \\
\hline 9450 & 0 & 9684.5 & 2070.25 & 83268330 & 9450 & 0.4705 & 9684.5 & 2777.375 & 84833740 \\
\hline 9450 & 0 & 9684.5 & 2777.375 & 82782820 & 9450 & 0.4705 & 9684.5 & 3484.5 & 84877630 \\
\hline 9450 & 0 & 9684.5 & 3484.5 & 83268330 & 9450 & 0.4705 & 19142 & 2070.25 & 85431890 \\
\hline 9450 & 0 & 19142 & 2070.25 & 83268330 & 9450 & 0.4705 & 19142 & 2777.375 & 84883720 \\
\hline 9450 & 0 & 19142 & 2777.375 & 82749290 & 9450 & 0.4705 & 19142 & 3484.5 & 84830430 \\
\hline 9450 & 0 & 19142 & 3484.5 & 82747410 & 18900 & 0 & 9684.5 & 2070.25 & 83268330 \\
\hline 9450 & 0.4705 & 9684.5 & 2070.25 & 85431890 & 18900 & 0 & 9684.5 & 2777.375 & 82720390 \\
\hline 9450 & 0.4705 & 9684.5 & 2777.375 & 84833740 & 18900 & 0 & 9684.5 & 3484.5 & 82720390 \\
\hline 18900 & 0.4705 & 19142 & 2070.25 & 85431890 & 18900 & 0 & 19142 & 2070.25 & 83268330 \\
\hline 18900 & 0.4705 & 19142 & 2777.375 & 84864790 & 18900 & 0 & 19142 & 2777.375 & 82720390 \\
\hline 18900 & 0.4705 & 19142 & 3484.5 & 84864790 & 18900 & 0 & 19142 & 3484.5 & 82720390 \\
\hline 18900 & 0.4705 & 9684.5 & 2777.375 & 84820870 & 18900 & 0.4705 & 9684.5 & 2070.25 & 85431890 \\
\hline- & - & - & - & - & 18900 & 0.4705 & 9684.5 & 3484.5 & 84918810 \\
\hline
\end{tabular}
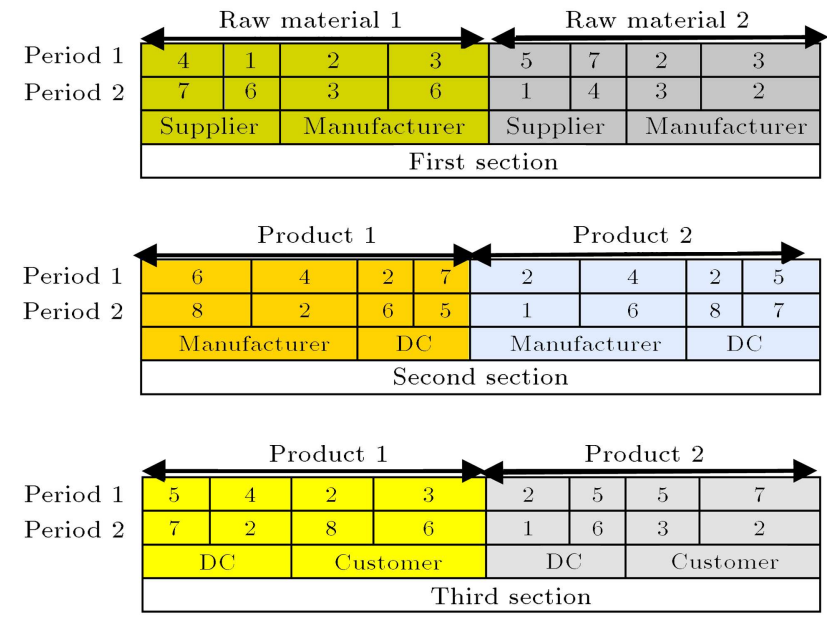

Figure 2. Sample of chromosome representation.

\begin{tabular}{|c|c|c|c|c|c|c|c|c|}
\hline \multirow{4}{*}{$\begin{array}{l}\text { Period } 1 \\
\text { Period } 2\end{array}$} & \multicolumn{4}{|c|}{ Product 1} & \multicolumn{4}{|c|}{ Product 2} \\
\hline & 5 & 4 & 2 & 3 & 2 & 5 & 5 & 7 \\
\hline & 7 & 2 & 8 & 6 & 1 & 6 & 3 & 2 \\
\hline & \multicolumn{2}{|c|}{$\mathrm{DC}$} & \multicolumn{2}{|c|}{ Customer } & \multicolumn{2}{|c|}{$\mathrm{DC}$} & \multicolumn{2}{|c|}{ Customer } \\
\hline
\end{tabular}

Figure 3. Chromosome representation.

$D)$ ]. Figure 3 represents an example of a chromosome for a supply chain which includes two distributors, customers, products, and periods. To enhance the feasible solutions according to the main goal of this model for satisfying customers' demand, the maximum allele value is selected. Then, the delivery quantity between customers and distribution centers is obtained. After selecting the maximum allele value, a heuristic method is proposed to evaluate the fitness value of chromosomes. Using the steps of the proposed method, feasible chromosomes that satisfy all constraints except Constrain (15) are generated. To fit the problem at hand, Pasandideh et al. [17] used encoding and decoding procedure and modified it based on the model formulation at hand.

According to a gene selected with the maximum number (customer with most demands or distribution center with high capacity) of chromosomes, there are some decisions as follows:

- Step 1. The best distribution centers are allocated to customers according to transportation costs, time between distribution centers and selected customer. Regarding the customers' demand rates, distribution center's capacity, vehicle deliverable quantities while minimizing the ratio of received items to demand rate, the number of their deliveries is examined. After updating unsatisfied demands and distribution center's capacity, if capacities are more than zero, this step will be repeated until the capacity or total demands of customers reach zero. The delivery quantities between customers and DCs, shortages and distribution centers' inventories will be obtained in this step. This step meets Constraints (18), (19), and (23);

- Step 2. Considering the inventory and shortage levels of manufacturing plants as equal to zero and removing unselected distribution centers from the list, manufacturing plants will be selected according to manufacturing and transportation time and costs. There are many factors affecting the delivery quantity between manufacturers and distributors. The capacity of distributors and manufacturers is one of these factors. Moreover, vehicles will be selected according to their capacities and risk. Inventory levels of plants, delivery quantities, perfect and imperfect items, and defective product numbers 
are examined while minimizing the ratio of the delivery quantity and demand between plants and distributors. Constraints (16)-(17) and (20)-(33) are met in this step;

- Step 3. According to purchase prices, allocated suppliers, plants, etc., the number of manufactured items, and percentage of used raw material for each product and delivery quantities are examined. Constraint (23) is met in this step.

\subsubsection{Evaluation}

In the proposed model, the maximum allowed risk limitation may cause infeasible solutions. Eq. (15) is another constraint which may cause infeasibility of solutions because it is not satisfied by using the proposed steps of heuristic methods. In order to avoid the solutions that do not satisfy these constraints, the penalty function approach is employed by Mousavi et al. [27]. These penalty functions are added to the objective functions based on the sum of two squared of violation of these constraints which can be referred to [17]. Eqs. (36) and (37) show two employed violation formulas:

$$
\begin{aligned}
& E q_{1}=\left[\left(R_{m d t}^{f i} \times z_{m d t}^{f i}\right)-R(U)_{m d t}^{f i}\right]^{4}, \\
& E q_{2}=\left[\left(I_{m, t-1}^{i}+P_{m t}^{i}\right)-C_{m t}^{i}\right]^{4} .
\end{aligned}
$$

Using penalty functions, the fitness function vector is evaluated as in Eqs. (38) and (39):

If the individual is not in a feasible region:

$$
\text { Penalty }=E q_{1}^{2}+E q_{2}^{2} \text {. }
$$

If the individual is in a feasible region:

Penalty $=0$,

Fitness function vector $=\left\{\begin{array}{l}Z_{1}+\text { penalty function } \\ Z_{2}+\text { penalty function } \\ Z_{3}+\text { penalty function } \\ Z_{4}+\text { penalty function } \\ Z_{5}+\text { penalty function }\end{array}\right.$

\subsubsection{Crossover operator}

The crossover is done to explore new solution spaces. The SBX operator [32] uses a probability distribution around two parents to create two children solutions. Unlike other real-parameter crossover operators, SBX uses a probability distribution [33].

\subsubsection{Mutation operator}

Mutation is used to prevent the premature convergence and explore new solution spaces. In this study, polynomial mutation operator is used. The probability distribution is a polynomial function. The probability of creating a solution closer to the parent is more than the probability of creating one away from it. The shape of the probability distribution is directly controlled by an external parameter, and the distribution is not dynamically changed with iterations [34].

\subsubsection{Parameter tuning of NSGA-II}

Since the parameters of NSGA-II play an important role in the quality of an obtained solution, in this paper, Taguchi method is used for tuning. The Taguchi method is implemented to tune the parameters of the algorithm. The reason why Design Of Experiment (DOE) is selected, rather than the other approaches to conduct an experiment, is that it has a systematic planning of experiments. One of the important steps involved in Taguchi's technique is a selection of orthogonal array. This method is an efficient procedure that is developed as an alternative to the full factorial experimental design method [35]. There are two suggested ways in Taguchi method to analyze the results. First, analysis of variance that is used for experiments that are repeated once; second, Signalto-Noise ratio $(S / N)$ that is used for experiments with multiple runs [36]. In the second method, a statistical measurement, $S / N$, is used to evaluate the performance. Figures 3 and 4 represent mean of mean and $S / N$ ratios for this paper. Taguchi categorizes objective functions into three groups: the smaller the best type, the larger the best type, and nominal-is-the best type. Since cost function is of smaller-the-better type, its corresponding $S / N$ ratio is as in Eq. (40):

$$
S / N=-10 \log _{10}\left(\frac{\bar{y}}{S}\right)^{2}
$$

There are four parameters to be calibrated [37]; population size (nPop), number of iterations (maxiteration), and crossover, and mutation rates $\left(P_{c}\right.$ and $\left.P_{m}\right)$. These parameters with four levels are shown in Table 4 to run the experiments based on Taguchi design.

Table 5 represents Taguchi Experimental design for NSGA-II parameters.

The final analysis of experimental design is shown in Figures 5 and 6.

Finally, optimum levels for NSGA-II parameters are obtained as shown in Table 6 .

Table 4. Level of NSGA-II parameters.

\begin{tabular}{ccccc}
\hline $\begin{array}{c}\text { NSGA-II } \\
\text { parameters }\end{array}$ & Level 1 & Level 2 & Level 3 & Level 4 \\
\hline$P_{c}$ & 0.2 & 0.4 & 0.6 & 0.8 \\
$P_{m}$ & 0.02 & 0.04 & 0.07 & 0.1 \\
$n P o p$ & 60 & 90 & 120 & 150 \\
Max-iteration & 100 & 120 & 150 & 200 \\
\hline
\end{tabular}


Step 1:

For $i=1$ to number of manufactured items

For $t=1$ to number of periods

Select the maximum $o$ array from 1 to $C+D$

AND the range of matrix is: $[1, I \times(C+D)]$

Step 2:

For $t=1$ to number of periods

For $c=1$ to number of costumers

If $K^{*}=0$

$K^{*}=D_{c t}$

Goto Step 7

If $K^{*}=1$

Goto Step 3

Step 3:

For $d=1$ to number of distribution center

For $v=1$ to number of vehicle between $d, c$ For $c=1$ to number of costumer

$$
W=T(s)_{d_{c t}}^{v_{i}} \times C(T)_{d_{c t}}^{v_{i}}
$$

For minimum of $W$

$$
q_{d_{c t}}^{v_{i}}=\text { minimum of }\left(D_{c t}^{i}, C_{d t}^{i}, C_{t}^{v}\right)
$$

Step 4:

If $q_{d_{c t}}^{v_{i}}=C_{t}^{v} \quad Z_{d_{c t}}^{v_{i}}=1$

and for $v_{i} \neq v \quad Z_{d_{c t}}^{v_{i}}=0$

If $q_{d_{c t}}^{v_{i}} \neq C_{t}^{v}$

Find maximum of $C_{t}^{v}$ AND $Z_{d_{c t}}^{v_{i}}=1$

AND for all $v_{i} \neq v \quad Z_{d_{c t}}^{v_{i}}=0$

Step 5:

Now new value of $D_{c t}^{i}$ is:

For $v=1$ to number of vehicle between $d, c$

For $d=1$ to number of distribution center

$D_{c t}^{i}=$ old value of $D_{c t}^{i}-q_{d_{c t}}^{v_{i}}$

For $c=1$ to number of costumer

For $v=1$ to number of vehicle between $d, c$

$C_{d t}^{i}=$ old value of $C_{d t}^{i}-q_{d_{c t}}^{v_{i}}$

Now:

If new value of $C_{d t}^{i}>0$

Goto Step 1

If new value of $C_{d t}^{i}=0$

Goto Step 6

Step 6:

For $v=1$ to number of vehicle between $d, c$

For $i=1$ to number of manufactured item

For $c=1$ to number of costumer

For $t=1$ to number of period

For every $d$ that $q_{d i t}^{v_{i}}$ is zero:

Remove $d$ from list of $d$ and goto Step 7 .

Step 7:

For $d=1$ to number of distribution center

For $t=1$ to number of period

For $i=1$ to number of manufactured item

For $m$ that $C(T)_{m d t}^{f_{i}} \times T(S)_{m d t}^{f_{i}} \times T(P)_{m d t}^{f_{i}} \times R_{m d t}^{f_{i}}$

is minimum:

$q_{m d t}^{f_{i}}=$ minimum of $\left(D_{m d t}^{i}, C_{m t}^{i}, C_{t}^{f}\right)$ and goto Step 8
Step 8:

If $q_{m d t}^{f_{i}}=C_{t}^{f}$

for $f_{i}=f: Z_{m d t}^{f_{i}}=1$

for all $f_{i} \neq f: Z_{m d t}^{f_{i}}=0$

If $q_{m, t}^{f_{i}} \neq C_{t}^{f}$

Find maximum of $C_{t}^{f}$ AND for this $f$ :

$$
Z_{m d t}^{f_{i}}=1
$$

And for all $f_{i} \neq f: Z_{m d t}^{f_{i}}=0$

Step 9:

For $m=1$ to number of manufacturer

For $f=1$ to number of vehicle between $m, d$

New value of $D_{m d t}^{i}=$ old value of $D_{m d t}^{i}-q_{m d t}^{f_{i}}$

New value of $C_{m t}^{i}=$ old value of $C_{m t}^{i}-q_{m d t}^{f_{i}}$

If $C_{m t}^{i}>0$ goto Step 10

If $C_{m t}^{i}=0$ goto Step 11

Step 10:

For $t=1$ to number of period

For $d=1$ to number of distribution center

$$
L^{*}=D_{m d t}^{i}
$$

If $L^{*}>0$ goto Step 8

If $L^{*}=0$ goto Step 11

Step 11:

For $d=1$ to number of distribution center

For $t=1$ to number of period

For $i=1$ to number of manufactured item

For $f=1$ to number of vehicle between $m, d$

For every $m$ that $q_{m d t}^{f_{i}}=0$

Remove $m$ AND goto Step 12

Step 12:

For $d=1$ to number of distribution center

For $t=1$ to number of period

For $i=1$ to number of manufactured item

For $f=1$ to number of vehicle between $m, d$

For $m=1$ to number of manufacturer

$C_{d t}^{i}-q_{m d t}^{f_{i}}=I_{d t}^{i}$ AND goto Step 13

Step 13:

For $d=1$ to number of distribution center

For $t=1$ to number of period

For $i=1$ to number of manufactured item

For $f=1$ to number of vehicle between $m, d$

AND:

$$
I_{m t}^{i}+I_{m, t-1}^{i}=C_{m t}^{i}-q_{m d t}^{f_{i}}
$$

$$
P_{m t}^{i}=I_{m t}^{i}+q_{m d t}^{f_{i}}
$$

Step 14:

For $m=1$ to number of manufacturer

For $s=1$ to number of supplier

For $t=1$ to number of period

Find minimum of $\left(C(P)_{s m t}^{i^{\prime}}\right)$

AND this $S: q_{s m t}^{i^{\prime}}=P_{m t}^{i} \times R M P^{i i^{\prime}}$

Figure 4. Pseudo-code of NSGA-II. 
Table 5. Taguchi experimental design for NSGA-II parameters.

\begin{tabular}{cccccc}
\hline $\begin{array}{c}\text { Run } \\
\text { order }\end{array}$ & $\boldsymbol{P}_{\boldsymbol{c}}$ & $\boldsymbol{P}_{\boldsymbol{m}}$ & $\boldsymbol{n P o p}$ & Max-iteration & Fitness 62 \\
\hline 1 & 0.2 & 0.1 & 60 & 100 & 0.471691 \\
2 & 0.2 & 0.04 & 90 & 120 & 0.563501 \\
3 & 0.2 & 0.07 & 120 & 150 & 0.564812 \\
4 & 0.2 & 0.02 & 150 & 200 & 0.226407 \\
5 & 0.4 & 0.02 & 90 & 150 & 0.496602 \\
6 & 0.4 & 0.04 & 60 & 200 & 0.351070 \\
7 & 0.4 & 0.07 & 150 & 100 & 0.356001 \\
8 & 0.4 & 0.1 & 120 & 120 & 0.276391 \\
9 & 0.6 & 0.02 & 120 & 200 & 0.540974 \\
10 & 0.6 & 0.04 & 150 & 150 & 0.538279 \\
11 & 0.6 & 0.07 & 60 & 120 & 0.543718 \\
12 & 0.6 & 0.1 & 90 & 100 & 0.357596 \\
13 & 0.8 & 0.02 & 150 & 120 & 0.350830 \\
14 & 0.8 & 0.04 & 120 & 100 & 0.474895 \\
15 & 0.8 & 0.07 & 90 & 200 & 0.411590 \\
16 & 0.8 & 0.1 & 60 & 150 & 0.709102 \\
\hline
\end{tabular}

Table 6. NSGA-II optimum parameters.

\begin{tabular}{cccc}
\hline $\boldsymbol{P}_{\boldsymbol{c}}$ & $\boldsymbol{P}_{\boldsymbol{m}}$ & $\boldsymbol{n P o p}$ & Max-It \\
\hline 0.4 & 0.1 & 150 & 200 \\
\hline
\end{tabular}

\subsection{Numerical results}

Consider a multi-period SC with multiple suppliers, manufacturers, distribution centers, and customers. The suppliers produce more than one raw material and plants manufacture several items under customer demand uncertainty. Some problem instances are generated as shown in Table 7.

Parameters' corresponding ranges of the mentioned problem instances are shown in Table 8. These parameters are generated randomly by using some related literature reviews.

As mentioned before, the demands of customers

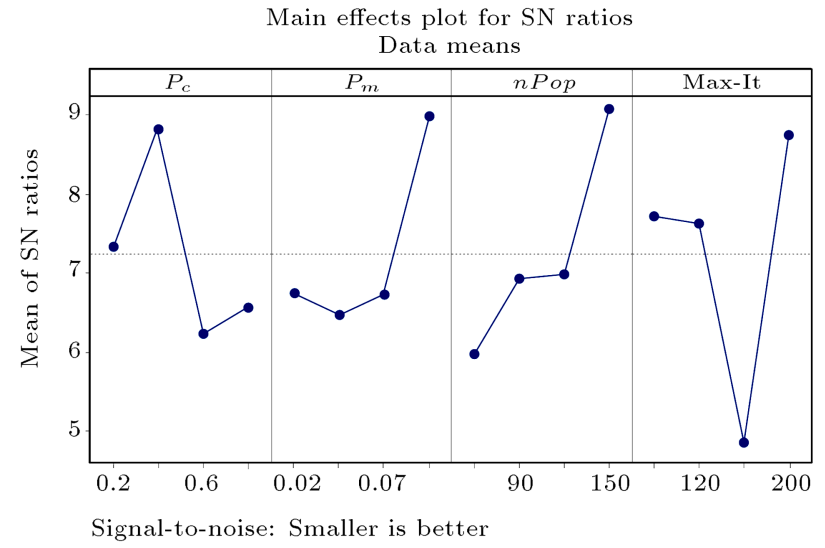

Figure 5. Plots of main effects for $S / N$ ratios of NSGA-II.

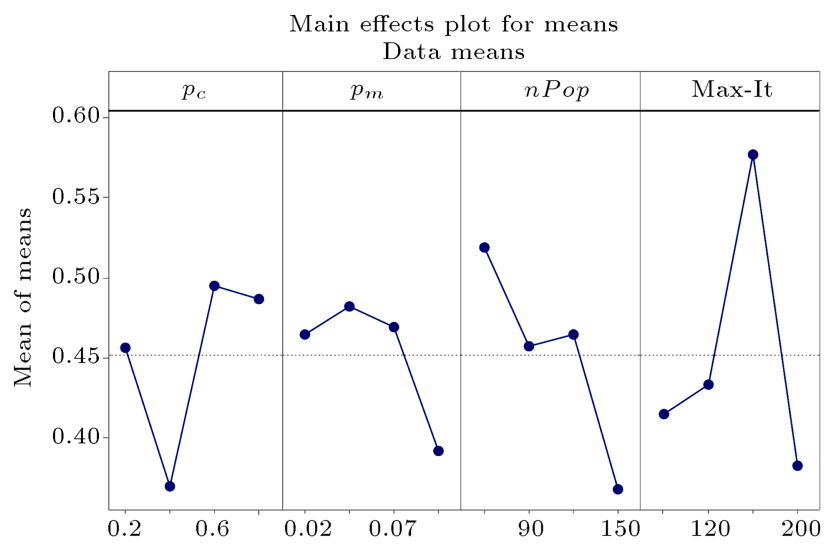

Figure 6. Plots of main effects for means of NSGA-II.

are considered as trapezoidal fuzzy numbers to make the model more realistic while considering the uncertainty. These fuzzy data are defuzzified after generating, and then are used. To do this, the mean-max membership method is employed. Interested readers are referred to [38] to read more.

These instances are firstly solved by $\varepsilon$-constrain method by GAMS software on a corei 5 processor, $4 \mathrm{G}$ RAM and $2.4 \mathrm{GHz}$ PC. The problem is computationally intractable and GAMS was unable to find solutions

Table 7. Generated problem instances.

\begin{tabular}{lllll}
\hline & \multicolumn{3}{c}{ Problem } & no. \\
\cline { 2 - 5 } & $\mathbf{1}$ & $\mathbf{2}$ & $\mathbf{3}$ & $\mathbf{4}$ \\
\hline Raw materials & 2 & 2 & 2 & 2 \\
Manufactured items & 2 & 2 & 2 & 2 \\
Suppliers & 2 & 2 & $\mathbf{4}$ & $\mathbf{4}$ \\
Manufacturers & 2 & 2 & 2 & 2 \\
Distribution centers & 2 & $\mathbf{3}$ & $\mathbf{3}$ & $\mathbf{3}$ \\
customers & 2 & 2 & 2 & $\mathbf{4}$ \\
Number of vehicles between plants and DCs & 2 & 2 & 2 & 2 \\
Number of vehicles between DCs and customers & 2 & 2 & 2 & $\mathbf{3}$ \\
\hline
\end{tabular}


Table 8. Parameters ranges for SC.

\begin{tabular}{llllll}
\hline Parameter & \multicolumn{1}{c}{ Range } & Parameter & Range & Parameter & Range \\
\hline$O_{m d t}^{i}:$ & {$[400,510]$} & $C(P 1)_{m d t}^{f i}:$ & {$[500,570]$} & $P(S)_{m d t}^{f i}:$ & {$[0.25,0.6]$} \\
$R M P^{i^{\prime} i}:$ & {$[40,50]$} & $C(P 2)_{m d t}^{f i}:$ & {$[400,550]$} & $C_{t}^{v}:$ & 250 \\
$D_{m d t}^{i}:$ & {$[720,900]$} & $C(P)_{s m t}^{i^{\prime}}:$ & {$[300,370]$} & $C_{d t}^{i}:$ & {$[750,840]$} \\
$D_{c t}^{i}:$ & {$[1000,1900]$} & $\pi_{m d t}^{f i}:$ & {$[200,270]$} & $C_{m t}^{i}:$ & {$[2000,2800]$} \\
$D_{s m t}^{i^{\prime}}:$ & {$[650,850]$} & $C(M)_{m t}^{i}:$ & {$[400,500]$} & $C_{t}^{f}:$ & 250 \\
$T(P)_{m t}^{i}:$ & {$[1,2]$} & $C(H)_{m t}^{i}:$ & {$[650,900]$} & $E:$ & 3 \\
$T(S)_{m d t}^{f i}:$ & {$[5,7]$} & $C(H)_{m t}^{i^{\prime}}:$ & {$[800,950]$} & $X 2:$ & 0.03 \\
$T(S)_{d c t}^{v i^{\prime}}:$ & {$[5,7]$} & $C(H)_{d t}^{i}:$ & {$[250,400]$} & $X 1:$ & 0.02 \\
$C(T)_{m d t}^{f i}$ & {$[600,660]$} & $C(T)_{t}^{f}:$ & {$[100,150]$} & $R(U)_{m d t}^{f i}:$ & {$[300,390]$} \\
$C(T)_{d c t}^{v i}$ & {$[500,560]$} & $I R_{m d t}^{f i}:$ & {$[270,300]$} & $C(Q)_{m t}^{i}$ & {$[700,950]$} \\
\hline & & & & &
\end{tabular}

Table 9. Computational results of the $\varepsilon$-constrain method and NSGA-II algorithm.

\begin{tabular}{|c|c|c|c|c|c|c|c|c|c|c|c|c|}
\hline \multirow{2}{*}{$\begin{array}{c}\text { Problem } \\
\text { no. }\end{array}$} & \multicolumn{6}{|c|}{$\varepsilon$-constraint } & \multicolumn{5}{|c|}{ NSGA-II } & \multirow[b]{2}{*}{$\begin{array}{l}\text { CPU } \\
\text { time }\end{array}$} \\
\hline & $Z_{1}$ & $Z_{2}$ & $Z_{3}$ & $Z_{4}$ & $Z_{5}$ & $\begin{array}{l}\text { CPU } \\
\text { time }\end{array}$ & $Z_{1}$ & $Z_{2}$ & $Z_{3}$ & $Z_{4}$ & $Z_{5}$ & \\
\hline 1 & 55628950 & 123 & 4241.747 & 0.467 & 1975.500 & $330(\mathrm{~s})$ & 64671320 & 141 & 4601.500 & 0.402 & 2010.300 & 252 \\
\hline 2 & 83441600 & 185 & 6613.481 & 0.470 & 2442.250 & $1015(\mathrm{~s})$ & 90510100 & 201 & 6923.359 & 0.422 & 2523.102 & 335 \\
\hline 3 & 84820870 & 345.825 & 6860 & 0.470 & 2653.750 & $1023(\mathrm{~s})$ & 967704000 & 403 & 7001.200 & 0.426 & 2823.840 & 387 \\
\hline 4 & $\begin{array}{c}\text { Cannot } \\
\text { solve }\end{array}$ & $\begin{array}{c}\text { Cannot } \\
\text { solve }\end{array}$ & $\begin{array}{c}\text { Cannot } \\
\text { solve }\end{array}$ & $\begin{array}{c}\text { Cannot } \\
\text { solve }\end{array}$ & $\begin{array}{c}\text { Cannot } \\
\text { solve }\end{array}$ & - & 100895100 & 467 & 7433.550 & 0.426 & 2825.500 & 831 \\
\hline
\end{tabular}

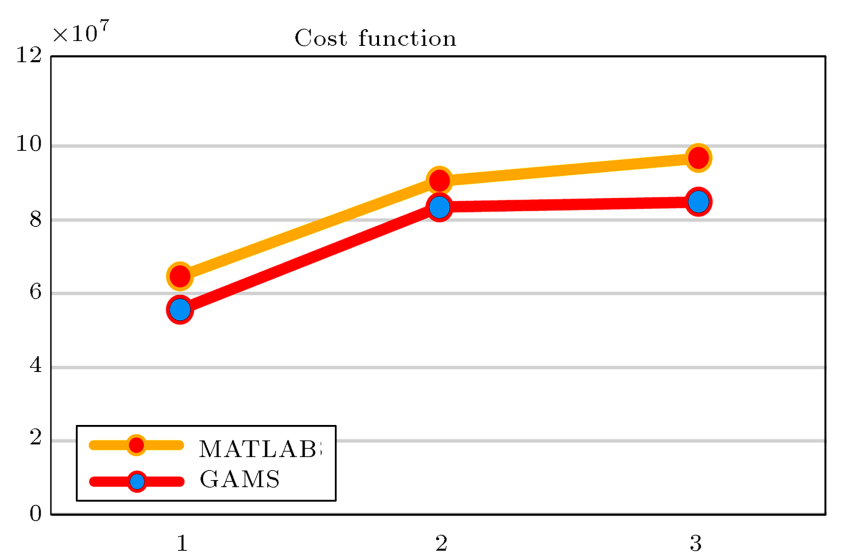

Figure 7. Graphical comparison of solving methodologies in terms of cost function.

to larger than medium-sized problems. Therefore, NSGA-II was employed to solve them by MATLAB. The comparison of these methodologies is shown in Table 9 and Figures 6 to 11.

Figures 7-12 present the comparison of methodologies between five objective functions of the proposed models in Section 4. Figure 8 shows CPU time of solving methods. This figure shows that NSGA-II is applicable to solve the fourth problem instance, not solved by $\varepsilon$-constraint method. Since this new model is more complicated with five objectives and more number of constraints, NSGA-II is applicable to mediumsized problems and represent reasonable solutions.

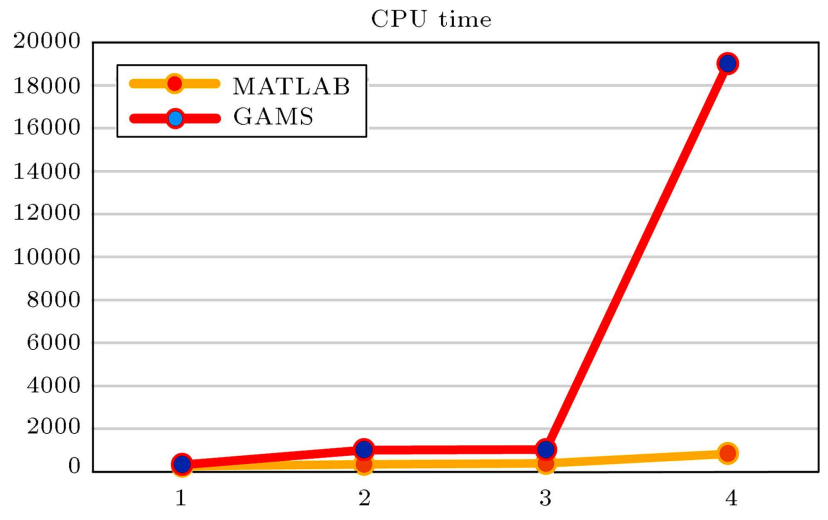

Figure 8. Graphical comparison of solving methodologies in terms of CPU time.

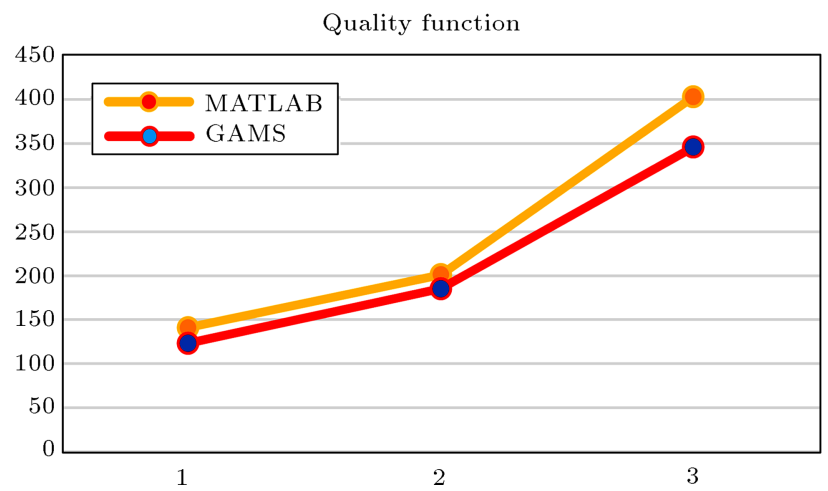

Figure 9. Graphical comparison of solving methodologies in terms of quality function. 


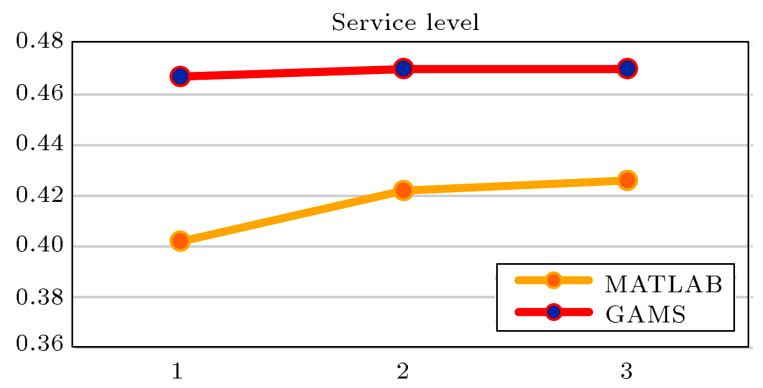

Figure 10. Graphical comparison of solving methodologies in terms of service level function.

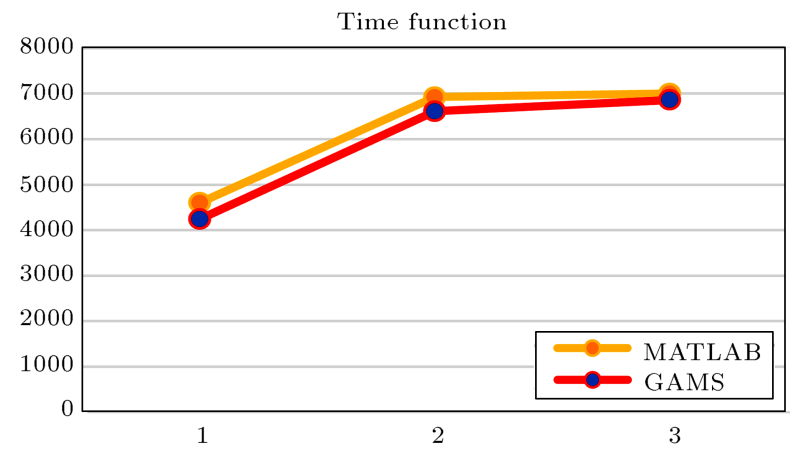

Figure 11. Graphical comparison of solving methodologies in terms of time function.

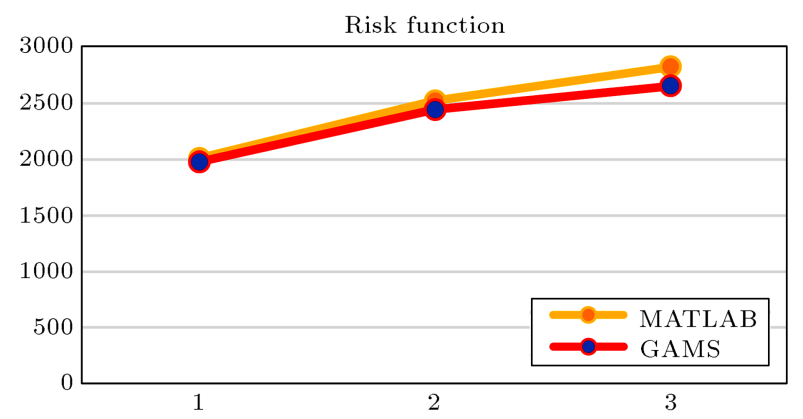

Figure 12. Graphical comparison of solving in terms of risk function.

When a NSGA-II is used for optimizing a multiobjective mathematical model, a set of Pareto solutions is provided. The Pareto solutions obtained by every iteration while using suggested algorithm are shown in Figures 13-16. These figures show the trade-off between cost functions and other objective functions for the third problem instance each in one curve.

The most important issue about each metaheuristic algorithm is the best value. After more than one hundred runs, the best combination is obtained as Table 9. The convergence path of NSGA-II is plotted in Figure 17.

To evaluate the performances of the proposed approaches, three standard metrics of multi-objective algorithms are applied. In order to compare the obtained results and objective functions' behavior diversity, CPU time and NOS metrics are used for Pareto

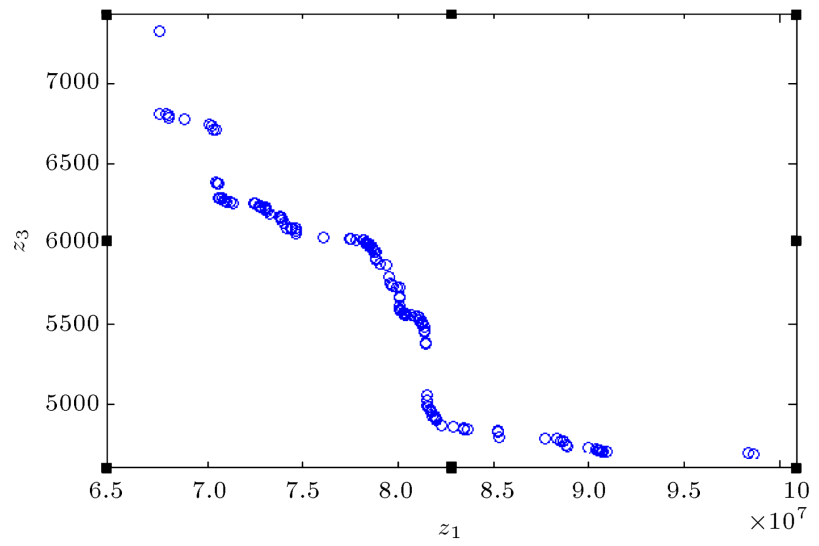

Figure 13. Pareto-optimal solution of NSGA-II for minimizing cost and defective and imperfect items.

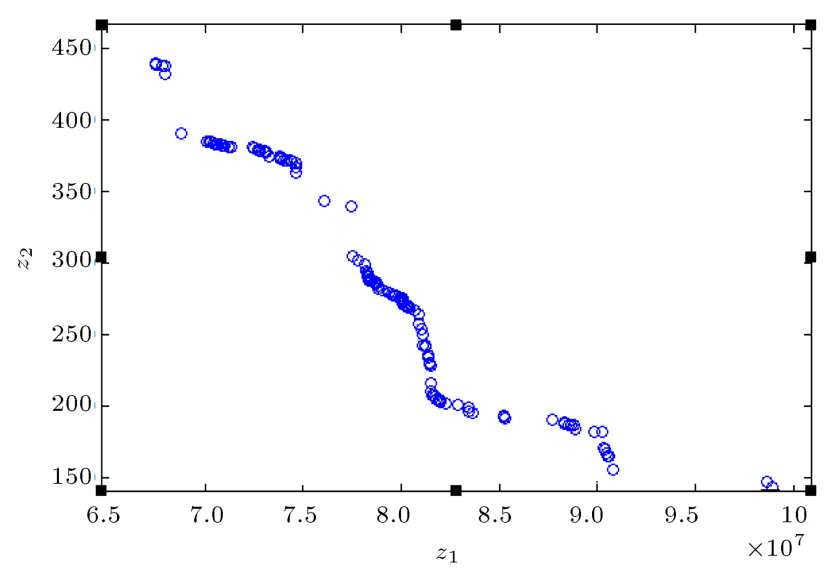

Figure 14. Pareto-optimal solution of NSGA-II for minimizing cost and time.

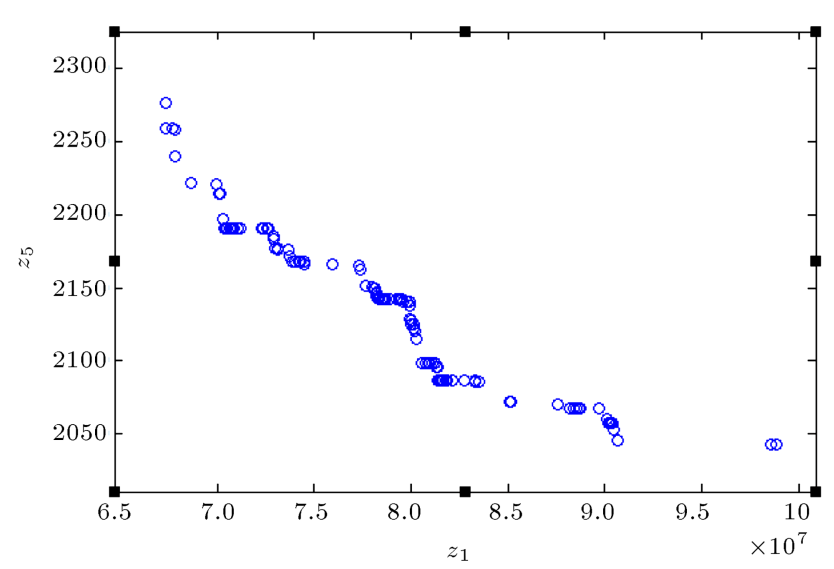

Figure 15. Pareto-optimal solution of NSGA-II for minimizing costs and risk.

solutions. Diversity measures the extension of the Pareto front, in which the bigger value is better [39]. NOS counts the number of Pareto solutions in the Pareto optimal front in which the bigger value is better [40]. CPU time shows the time of running the approaches to reach near-optimum solutions. Table 10 represents the spread of curves for $\varepsilon$-constraint and 
Table 10. Comparison of the obtained results of the $\varepsilon$-constrain method and NSGA-II algorithm.

\begin{tabular}{cccccccc}
\hline \multirow{2}{*}{$\begin{array}{c}\text { Problem } \\
\text { no. }\end{array}$} & \multicolumn{3}{c}{$\varepsilon$-constraint } & & \multicolumn{3}{c}{ NSGA-II } \\
\cline { 2 - 3 } & Diversity & CPU time (s) & NOS & & Diversity & CPU time (s) & NOS \\
\hline 2 & $8.8609 \mathrm{E}+08$ & 330 & 64 & & $8.1872 \mathrm{E}+08$ & 252 & 72 \\
3 & $4.2341 \mathrm{E}+08$ & 1015 & 63 & & $3.0681 \mathrm{E}+08$ & 335 & 72 \\
4 & $3.4912 \mathrm{E}+08$ & 1023 & 63 & & $3.2601 \mathrm{E}+08$ & 387 & 74 \\
\hline
\end{tabular}

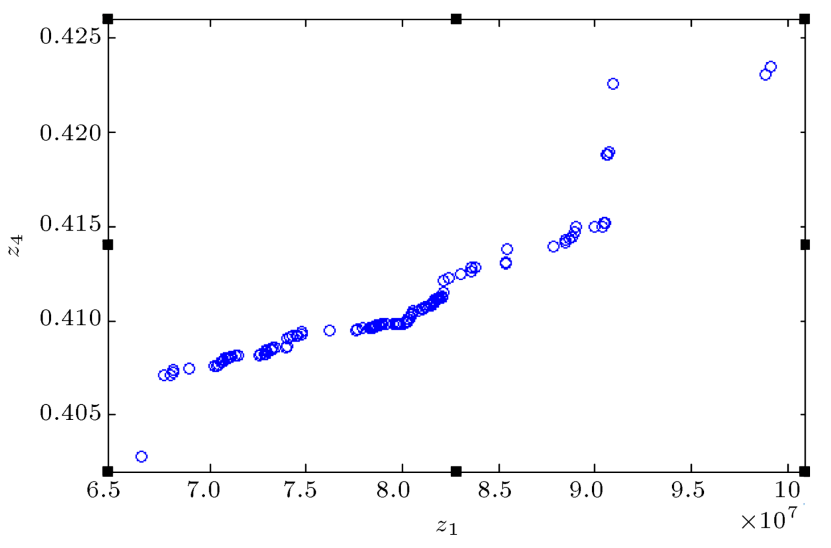

Figure 16. Pareto-optimal solution of NSGA-II for minimizing cost and maximizing service level.

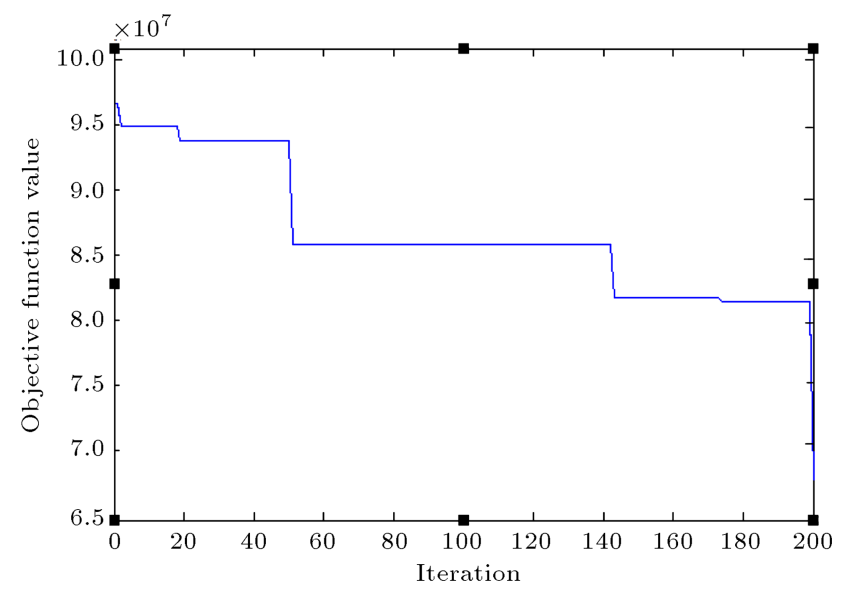

Figure 17. The convergence path of the best result by NSGA-II.

NSGA-II. This table also shows CPU time consumed to solve problem instances by the two mentioned methodologies and NOS metrics.

Sensitivity analysis is utilized to asses parameters' effects on objective functions. The value of the parameters is changed in the interval $(-30 \%, 30 \%)$. Sensitivity analysis results show that the most effective parameter on cost function is $D_{m d t}^{i}$. Parameters $R M P^{i^{\prime} i}$ and $P s$ are the most effective ones in quality and time functions, respectively. $T(P)_{m t}^{i}$ and $I R$ are two parameters which affect risk function. Figures 1820 show the most effective parameter in cost and time objective functions.

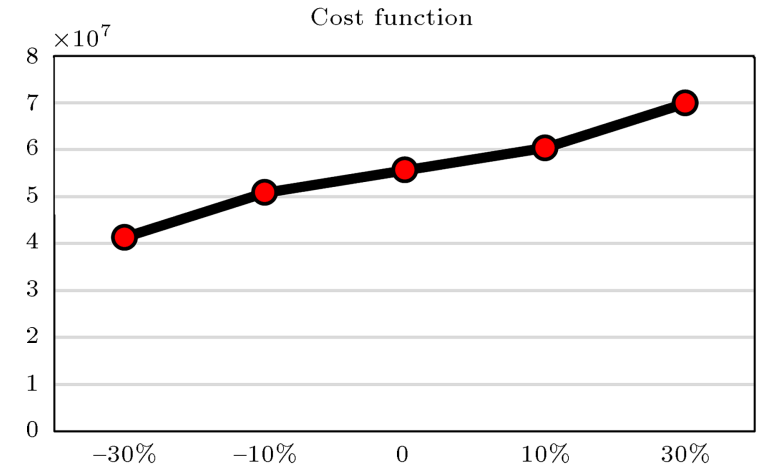

Figure 18. Trend of quality function based on parameter $D_{m d t}^{i}$.

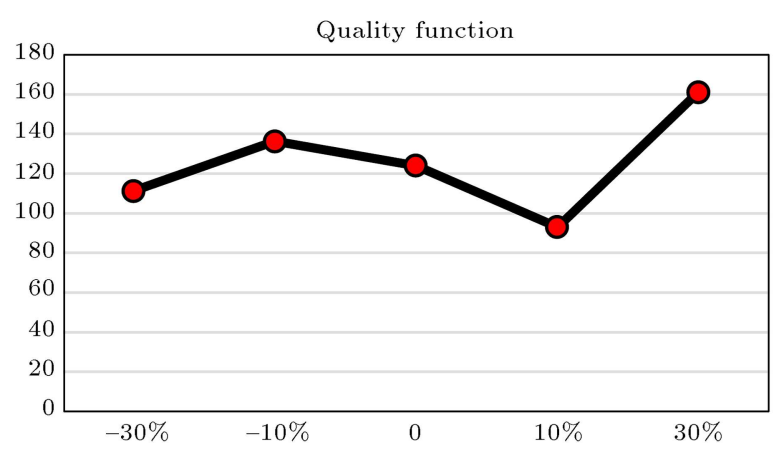

Figure 19. Trend of cost function based on parameter $R M P^{i^{\prime} i}$.

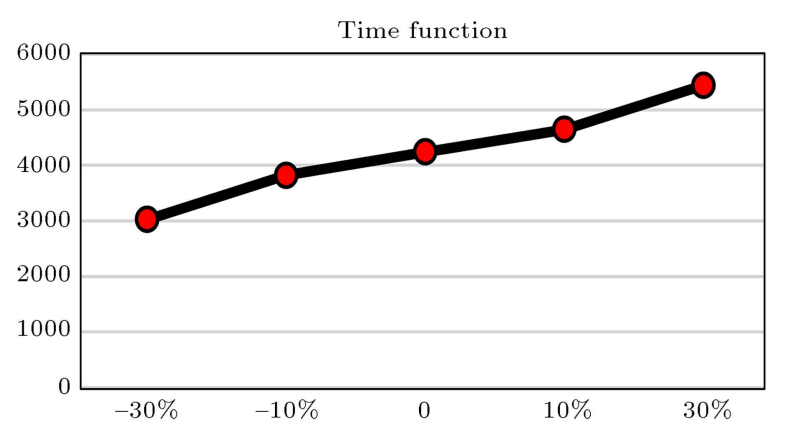

Figure 20. Trend of risk function based on parameter Ps.

\section{Conclusion and future research}

In this paper, a new multi-objective mixed-integer nonlinear programming was presented for a multi-item multi-period SCM problem. It was assumed that demand rates are fuzzy values.

The aim was to maximize customer satisfaction 
and minimize the total costs. An exact method and a meta-heuristic algorithm were used to solve the proposed model. Furthermore, a Taguchi method was utilized to calibrate NSGA-II parameters. The obtained results show the validity of the suggested solving methods. Four numerical examples were solved and compared by two solving methods based on two measures: value of objective functions and CPU time. While $\varepsilon$-constraint was unable to solve the last problem, NSGA-II was able to solve it and provide Pareto front solutions.

As for further research directions, it is suggested to consider these assumptions:

- Utilizing engineering economic techniques, such as inflation rate, to calculate the costs exactly;

- Considering networks of suppliers and distributors instead of layers of some nodal enterprises;

- Using green supply chain concepts to reduce environment's pollution; performing a real-situation case study;

- Utilizing some other meta-heuristic algorithms and comparing the obtained results to find the best solving method.

\section{References}

1. Pasandideh, S.H.R., Niaki, S.T.A. and Asadi, K. "Optimizing a bi-objective multi-product multi-period three layer supply chain network with warehouse reliability", Expert Systems with Applications, 42(5), pp. 2615-2623 (2015).

2. Shirani, A., Danaei, H. and Shirvani, A. "A study on different factors influencing customer satisfaction on industrial market", Management Science Letters, 4(1), pp. 139-144 (2014).

3. Deb, K., Agrawal, S., Pratap, A. and Meyarivan, T. "A fast elitist non-dominated sorting genetic algorithm for multi-objective optimization: NSGA-II", In Proceedings of Parallel Problem Solving, 1917, pp. 489-858 (2000).

4. Abounacer, R., Rekik, M. and Renaud, I. "An exact solution approach for multi-objective locationtransportation problem for disaster response", Computers and Operations Research, 41, pp. 25-39 (2014).

5. Harris, W. "How many parts to make at once? Factory", The Magazine of Management, 10, pp. 135-152 (1913).

6. Miller, L. "A multi-item inventory model with joint backorder criterion", Operations Research, 19(6), pp. 1467-1476 (1971).

7. Kirkpatrick, S., Gelatt, C.D. and Vecchi, M.P. "Optimization by simulated annealing", Science, 220, pp. 671-680 (1983).
8. Das, K., Roy, T.K. and Maiti, M. "Multi-item inventory model with quantity-dependent inventory costs and demand-dependent unit cost under imprecise objective and restrictions: a geometric programming approach", Production Planning and Control, 11(8), pp. 781-788 (2000).

9. Clark, A. and Scarf, H. "Optimal policies for a multilayer inventory problem", Management Sciences, 6(4), pp. 475-490 (1960).

10. Bessler, S. and Veinott, A.F. "Optimal policy for a dynamic multi-layer inventory model", Naval Research Logistics Quarterly, 13(4), pp. 355-389 (1965).

11. Goyal, S.K. "An integrated inventory model for a single supplier-single customer problem", International Journal of Production Research, 15(1), pp. 107-111 (1977).

12. Hsiao, J.M., and Lin, C. "A buyer-vendor EOQ model with changeable lead time in supply chain", International Journal of Advanced Manufacturing and Technology, 26(7), pp. 917-921 (2005).

13. Abdul-Jalbar, B., Gutiérrez, J.M. and Sicilia, J. "Policies for a single-vendor multi-buyer system with finite production rate", Decision Support Systems, 46(1), pp. 84-100 (2008).

14. Taleizadeh, A., Niaki, S.T.A. and Makui, A. "Multiproduct multiple-buyer single-vendor supply chain problem with stochastic demand, variable lead-time, and multi-chance constraint", Expert Systems with Applications, 39(26), pp. 5338-5348 (2012).

15. Sadeghi, J., Mousavi, S.M., Niaki, S.T.A. and Sadeghi, S. "Optimizing a multi-vendor multi-retailer vendor managed inventory problem: Two tuned metaheuristic algorithms", Knowledge-Based Systems, 50, pp. $159-170$ (2013).

16. Varyani, A., Jalilvand-Nejad, A. and Fattahi, P. "Determining the optimum production quantity in threelayer production system with stochastic demand", International Journal of Advanced Manufacturing Technology, 72(1), pp. 119-133 (2014).

17. Pasandideh, S.H.R., Niaki, S.T.A. and Asadi, K. "Biobjective optimization of a multi-product multi-period three-layer supply chain problem under uncertain environments: NSGA-II and NRGA", Information Sciences, 292(7), pp. 57-74 (2015).

18. Pasandideh, S.H.R., Niaki, S.T.A. and Asadi, K. "Optimizing a bi-objective multi-product multi-period three layer supply chain network with warehouse reliability", Expert Systems with Applications, 42(5), pp. 2615-2623 (2015).

19. Sadeghi, J. and Niaki, S.T.A. "Two parameter tuned multi-objective evolutionary algorithms for a bi-objective vendor managed inventory model with trapezoidal fuzzy demand", Applied Soft Computing, 30, pp. 567-576 (2015).

20. Sarrafha, K., Rahmati, S.H.A., Niaki, S.T.A. and Zaretalab, A. "Bi-objective integrated procurement, 
production, and distribution problem of a multi-layer supply chain network design: a new tuned MOEA", Computers \& Operations Research, 54, pp. 35-51 (2015).

21. Suchánek, P., Richter, J. and Králová2, M. "Customer satisfaction" product quality and performance of companies", Review of Economic Perspectives Národohospodáský Obzor, 14(4), pp. 329-344 (2015).

22. Kamali, A., Fatemi Ghomi, S.M.T. and Jolai, F. "A multi-objective quantity discount and joint optimization model for coordination of a single-buyer multivendor supply chain", Computers and Mathematics with applications, 62(20), pp. 3251-3262 (2011).

23. Mortezaei, N., Zulkifli, N. and Nilashi, M. "Tradeoff analysis for multi-objective aggregate production planning", Journal of Soft Computing and Decision Support System, 2(2), pp. 1-4 (2015).

24. Arabzad, S.M., Ghorbani, M.R. and TavakkoliMoghaddam, R. "An evolutionary algorithm for a new multi-objective location-inventory model in a distribution network with transportation modes and third-party logistics providers", International Journal of Production Research, 53(4), pp. 1038-1050 (2014).

25. Sadeghi, J., Sadeghi, S. and Niaki, S.T.A. "Optimizing a hybrid vendor-managed inventory and transportation problem with fuzzy demand: An improved particle swarm optimization algorithm", Information Sciences, 272, pp. 126-144 (2014).

26. Sadeghi, J. and Niaki, S.T.A. "Two parameter tuned multi-objective evolutionary algorithms for a biobjective vendor managed inventory with trapezoidal fuzzy demand", Application of Soft Computing, 30, pp. 567-576 (2015).

27. Mousavi, M., Sadeghi, J., Niaki, S.T.A. and Tavanad, M. "A bi-objective inventory optimization model under inflation and discount using tuned Pareto-based algorithms: NSGA-II, NRGA, and MOPSO", Applied Soft Computing, 43, pp. 57-72 (2016).

28. Hassanzadeh, S. and Guoqing Zhang, A. "A multiobjective facility location model for closed-loop supply chain network under uncertain demand and return", Applied Mathematical Modelling, 37(6), pp. 4165-4176 (2013).

29. Saffar, M., Shakouri, H. and Jafar Razmi, G. "A new multi objective optimization model for designing a green supply chain network under uncertainty", International Journal of Industrial Engineering Computations, 6(1), pp. 15-32 (2015).

30. Yu, M.C. and Goh, M. "A multi-objective approach to supply chain visibility and risk", European Journal of Operational Research, 233(1), pp. 125-130 (2015).

31. Abounacer, R., Rekik, M. and Renaud, I. "An exact solution approach for multi-objective locationtransportation problem for disaster response", Computers and Operations Research, 41, pp. 25-39 (2014).
32. Altiparmak, F., Gen, M., Lin, L. and Paksoy, T. "A genetic algorithm approach for multi-objective optimization of supply chain networks", Computers \& Industrial Engineering, 51(16), pp. 196-215 (2006).

33. Deb, K. and Agrawal, S. "A Niched-Penalty Approach for Constraint Handling in Genetic Algorithms", Artificial Neural Nets and Genetic Algorithms, pp. 235-243 (1999).

34. Kannan, S., Baskar, S. and Murugan, P. "Application of NSGA-II algorithm to single-objective transmission constrained generation expansion planning", IEEE Transactions on Power System, 24(4) pp. 1790-1797 (2009).

35. Kaladhar1, M., Subbaiah, K.V., Srinivasa Rao, Ch. and Narayana Rao, K. "Application of Taguchi approach and utility concept in solving the multiobjective problem when turning AISI 202 austenitic stainless steel", Journal of Engineering Science and Technology Review, 4(1), pp. 55-61 (2011).

36. Mousavi, S.M., Hajipour, V., Niaki, S.T.A. and Alikar, N. "Optimizing multi-item multi-period inventory control system with discounted cash flow and inflation: Two calibrated meta-heuristic algorithms", Applied Mathematical Modeling, 37(1), pp. 2241-2256 (2013).

37. Roy, R., A Primer on the Taguchi Method, Society of Manufacturing Engineers, New York, USA (1990).

38. Fraley, S., Oom, M., Terrion, B. and Date, J.Z. "Design of experiments via Taguchi methods: orthogonal arrays", USA: The Michigan Chemical Process Dynamic and Controls Open text Book (2006).

39. Zitzler, E. and Thiele, L. "Multiob jective optimization using evolutionary algorithms - A comparative case study", Parallel Problem Solving from Nature, Germany, pp. 292-301 (1998).

40. Zitzler, E., Laumanns, M. and Thiele, L. "SPEA2: Improving the strength Pareto evolutionary algorithm, Evolutionary Methods for Design", Optimization and Control with Applications to Industrial Problems, Greece, pp. 95-100 (2001).

\section{Biographies}

Shabnam Fazli Besheli received her BSc degree in Industrial Engineering from the Iran University of Science and Technology, Behshar Branch in 2011. She is currently a student with a master degree in Industrial Engineering in Mazandaran Institute of Technology. Her research interests are multi-objective multi-product multi-period supply chain problems and customer Satisfaction and transportation risks.

Ramezan Nemati Keshteli holds BS, MS, and $\mathrm{PhD}$ degrees in Industrial Engineering from Khajeh Nasir University of Technology, Isfahan University of Technology and Tarbiat Modares University, respectively. His research interests include statistical quality 
control, multivariate decision-making, and artificial intelligence.

Saeed Emami holds BS, MS, and $\mathrm{PhD}$ degrees in Industrial Engineering from Isfahan University of Technology. His research interests include scheduling, multiple criteria decision-making, and facility location.
Seyedeh Mansooreh Rasouli received her BSc degree in Industrial Engineering from the Babol Noshirvani University of Technology in 2013. She is currently a student with a master degree in Industrial Engineering in Mazandaran Institute of Technology. Her research interests include optimizing multi-objective multi-period location-inventory control problem. 